\title{
Nuclear Localization of the Interferon-Inducible Protein Kinase PKR in Human Cells and Transfected Mouse Cells
}

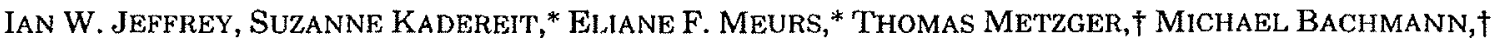 \\ Martin SCHWEMmLe, $\neq$ ARA G. Hovanessian, ${ }^{*}$ and MiCHAEL J. CLEMENS ${ }^{1}$ \\ Division of Biochemistry, St. George's Hospital Medical School, Cranmer Terrace, London SWI7 ORE, United Kingdom; ${ }^{*}$ Unité de Virologie \\ et d'Immunologie Cellulaire, Institut Pasteur, 75724 Paris Cédex 15, France; †Abteilung für Angewandte Molekularbiologie, Institut für \\ Physiologische Chemie, Universität Mainz, Duesbergweg 6, D-55099 Mainz, Federal Republic of Germany; and $\$$ Department \\ of Virology, Universität Freiburg, Hermann-Herderstrasse 11, D-79104 Freiburg, Federal Republic of Germany
}

The levels and subcellular distribution of the interferon-inducible double-stranded RNA-dependent protein kinase PKR have been measured in human Daudi cells and stably transfected mouse NIH $3 T 3$ cells expressing the human protein kinase. Immunofluorescence of intact cells and quantitative immunoblotting of cell extracts indicate that PKR occurs in both the cytaplasm and the cell nucleus, with staining specifically in the nucleolus. The ratio of cytoplasmic to nuclear PKR is approximately $5: 1$ in control cells; in response to interferon treatment the protein kinase is induced severalfold in the cytoplasm whereas the level in the nucleus does not increase significantly. Analysis of individual transfected cells by confocal microscopy reveals a pattern of distribution of PKR similar to that in Daudi cells, with immunostaining of cytoplasm and nucleoli. Similar results are observed whether cells expressing wild-type PKR or a catalytically inactive mutant form of the kinase are analyzed, but untransfected $3 \mathrm{~T} 3$ cells are not stained by the antibody used. Two-dimensional isoelectric focusing analysis of PKR in whole cell extracts reveals the presence of multiple forms with different $\mathrm{p} I$ values whereas similar analysis of the nuclear fraction indicates only one predominant species with a relatively basic $\mathrm{p} I$. These results suggest that PKR may have a role in the cell nucleus as well as the cytoplasm and that the subcellular distribution of the protein kinase may be related to post-translational modifications.

\section{INTRODUCTION}

The interferon (IFN)-inducible protein kinase PKR (formerly known as DAI, p68, P1, dsI, or $\mathrm{PK}_{\mathrm{ds}}$ ) has been the subject of intensive study in recent years because of its likely involvement in the antiviral and antiprolifera-

\footnotetext{
To whom correspondence and reprint requests should be addressed. Fax: 44-181725 2992.
}

tive effects of the IFNs [1-3]. PKR is critically dependent on low concentrations of double-stranded RNA (dsRNA) for its activation, a process which is accompanied by autophosphorylation of the enzyme at multiple sites $[4,5]$. When activated, PKR phosphorylates the $\alpha$-subunit of the eukaryotic protein synthesis initiation factor eIF-2 $[6,7]$. Phosphorylation of eIF- $2 \alpha$ contributes to the development of an antiviral state by inhibiting the activity of the guanine nucleotide exchange factor eIF-2B, thus impairing the overall rate of protein synthesis in infected cells $[8,9]$.

The importance of PKR in the antiviral effects of the IFNs is indicated by the fact that a number of viruses have evolved mechanisms for blocking the activation of PKR [10,11]. Examples of the strategies used are the production of large quantities of small virally encoded RNA species that bind to the protein kinase and inhibit the dsRNA-mediated activation process $[10,12]$, the synthesis of viral proteins that sequester dsRNA activators [13-15], and the virus-induced downregulation of PKR [16].

A potential role for $P K R$ in cell growth regulation has also been suggested by the observation that overexpression of the human enzyme inhibits cell proliferation [17]. Furthermore, high-level expression of catalytically inactive mutant forms of the kinase in $3 T 3$ cells converts the cells to a tumorigenic phenotype $[18,19]$. These findings have given rise to the idea that PKR may be a tumor suppressor gene product and that the PKR mutants exert a dominant negative effect on the activity of the wild-type enzyme [20]. Such an inhibitory effect of a PKR mutant has been demonstrated in vitro, and evidence has been presented that the basis of this effect is competition between the mutant and wild-type proteins for binding of dsRNA [21].

Double-stranded RNA also regulates a number of other pathways in mammalian cells. It binds to and is required for the activation of the $2^{\prime}, 5^{\prime}$-oligoadenylate synthetase family of IFN-inducible enzymes $[1,22]$ and it is an inducer of the transcription of several genes, in- 
cluding the IFN genes themselves [23, 24]. It is likely that activation of members of the NF- $\mathrm{NB}$ family of transcription factors by dsRNA involves PKR since antisense ablation of PKR mRNA inhibits this process [25].

Identification of the precise location of PKR within the cell may provide some clues to its role as a regulator of the antiviral state, as well as of cell proliferation and other processes. Earlier studies have shown that PKR is a cytoplasmic enzyme $[26,27]$ and that it is associated with the rough endoplasmic reticulum [27]. This is consistent with its identification as a ribosome-bound protein that can be washed off in high-salt buffers [28]. With the advent of immunofluorescence microscopy techniques using confocal laser scanning technology it has become possible to define the subcellular localization of this protein more precisely. In this paper we present evidence for the presence of human PKR additionally in the nucleus and nucleolus in a human cell line and in transfected mouse cells expressing the human protein. Induction of the protein kinase by IFN treatment results in an increase in the level of cytoplasmic PKR, almost all of which is associated with the ribosomes, whereas the amount of PKR in the nucleus does not increase significantly. The distribution of PKR between nucleus and cytoplasm correlates with differences in the extent of post-translational modification of the protein.

\section{MATERIALS AND METHODS}

Materials. Highly purified human IFN $\alpha\left(1-2 \times 10^{B}\right.$ International Reference Units/mg protein) was generously supplied by Wellcome Laboratories (Beckenham, UK) and Hoffman-LaRoche (Basel, Switzerland). A monoclonal antibody specific for human PKR (MAb 71/ $10)$ and murine polyclonal antibodies raised against purified human PKR were used as described previously $[29,30] .{ }^{125} \mathrm{I}$-labeled goat antimouse immunoglobulins, peroxidase-coupled sheep anti-mouse immunoglobulins, and $\left[{ }^{125} 1\right]$ streptavidin were supplied by Amersham International.

Cell culture. Human Daudi cells and mouse NIH-3T3 cells transfected with plasmids expressing wild-type or mutant forms of human PKR were cultured as described previously $[19,22,31,32]$. Where indicated, Daudi cells were treated with IFN $\alpha$ for up to $24 \mathrm{~h}$ prior to harvest.

Microscopic analysis of cells. Cells were fixed as described previously [27] and stained with the monoclonal anti-PKR antibody followed by a species-specific anti-mouse immunoglobulin labeled with the fluorochrome Cy3 (Dianova, Hamburg, Germany). Analysis was carried out by confocal laser scanning microscopy using a Zeiss LSM 10 microscope with a Plan-Neofluar $40 \times / 1.3$ oil objective as described [27]. For analysis of single cells the cells were automatically cut into horizontal sections at intervals of $0.75-1 \mu \mathrm{m}$ and evaluation of the stored stacks of horizontal optical sections was performed with the I.SM 10 image-processing unit.

Cell lysis and subcellular fractionation. For the preparation of total cell extracts Daudi cells were washed in phosphate-buffered saline (PBS) and then lysed in buffer containing $20 \mathrm{mM}$ Tris-HCl (pH 7.6), $50 \mathrm{mM} \mathrm{KCl}, 400 \mathrm{mM} \mathrm{NaCl}, 5 \mathrm{~m} M 2$-mercaptoethanol, $1 \%(\mathrm{v} / \mathrm{v})$ Triton $\mathrm{X}-100,1 \mathrm{mM}$ EDTA, $0.2 \mathrm{mM}$ PMSF, 100 units $/ \mathrm{ml}$ aprotinin, and $20 \%$ $(v / v)$ glycerol, as previously described [22]. For subcellular fractionation a procedure similar to that described previously [22] was employed. Daudi cells were washed in PBS and then lysed in hypotonic buffer (10 mM Tris-HCl, pH 7.6, $10 \mathrm{~m} M \mathrm{KCl}, 1 \mathrm{~m} M$ EDTA, $7 \mathrm{mM} 2$ mercaptoethanol, $0.2 \mathrm{mM}$ PMSF, $5 \mu \mathrm{g} / \mathrm{ml}$ leupeptin, $5 \mu \mathrm{g} / \mathrm{ml}$ pepstatin, and $1 \mathrm{mM}$ benzamidine). The concentration of $\mathrm{KCl}$ was then increased to $75 \mathrm{mM}$ and the cell lysates were centrifuged at $500 \mathrm{~g}$ for $10 \mathrm{~min}$ to give a nuclear pellet $(\mathrm{N})$. The supernatant was clarified by centrifugation at $2000 \mathrm{~g}$ for $10 \mathrm{~min}$ and a mitochondrial pellet (P12) was obtained by further centrifugation at $12,000 \mathrm{~g}$ for $20 \mathrm{~min}$. The supernatant was subsequently fractionated into a ribosomal pellet (P100) and postribosomal supernatant $(\mathrm{S} 100)$ at $100,000 \mathrm{~g}$ for $1 \mathrm{~h}$. The nuclear pellet was resuspended in $1 \mathrm{ml}$ of the above low-salt buffer containing $5 \mathrm{mM} \mathrm{MgCl}$, and Triton X-100 was added to $0.5 \%(\mathrm{v} / \mathrm{v})$. After $2 \mathrm{~min}$ the detergent-treated nuclei were washed twice by centrifugation $(200 \mathrm{~g}$, for $10 \mathrm{~min}$ ) and resuspension in $10 \mathrm{mM}$ Hepes (pH 7.4), $50 \mathrm{mM} \mathrm{KCl}, 1 \mathrm{mM} \mathrm{MgCl}$, $7 \mathrm{mM} 2$-mercaptoethanol, $20 \%$ (v/v) glycerol and then lysed in $400 \mu \mathrm{l}$ of $20 \mathrm{mM}$ Tris (pH 7.6), $50 \mathrm{mM} \mathrm{KCl}, 400$ $\mathrm{mM} \mathrm{NaCl}, 1 \%(\mathrm{v} / \mathrm{v})$ Triton X-100, 20\% (v/v) glycerol in the presence of PMSF, leupeptin, pepstatin, and benzamidine as above. After 30 $\mathrm{min}$ on ice the nuclear lysate was centrifuged at $10,000 \mathrm{~g}$ for $10 \mathrm{~min}$ and the supernatant retained for further analysis.

3T3 cells were scraped from the plates, lysed, and fractionated by procedures similar to those used for Daudi cells.

Immunoblotting. PKR levels in total cell extracts and subcellular fractions were determined by SDS-gel electrophoresis followed by immunoblotting, or by dot-blotting, using antibodies against human PKR as described previously $[29,30]$. Blots were incubated with either murine polyclonal antibodies raised against purified, urea-denatured PKR or the murine monoclonal antibody $71 / 10[29,30]$, followed by ${ }^{125}$ I-labeled goat anti-mouse immunoglobulins, peroxidase-coupled sheep anti-mouse immunoglobulins, or biotinylated goat anti-mouse IgG and [ [ $\left.{ }^{125} \mathrm{I}\right]$ streptavidin. PKR levels were determined by autoradiography, by diaminobenzidine/peroxide staining of the immunoblots, or by direct measurement of bound radioactivity on dot-blots, as ap propriate. In the latter case the blots were also calibrated with a series of standards prepared from purified recombinant baculovirus-synthesized PKR [33].

Isnelectric focusing analysis. Total cell and nuclear extracts from Daudi cells were separated by two-dimensional gel electrophoresis employing isoelectric focusing in the first dimension followed by separation according to size in the presence of SDS in the second dimension [22]. The $\mathrm{pH}$ gradient in the first dimension was between $\mathrm{pH} 5$ and 9 . The proteins were then subjected to analysis by immunoblotting using murine polyclonal antibodies against human PKR, followed by autoradiography, as above.

\section{RESULTS}

The pattern of PKR expression in Daudi Burkitt's lymphoma cells before and after IFN treatment has been analyzed by immunofluorescence microscopy using a monoclonal antibody specific for human PKR. Daudi cells are particularly sensitive to growth regulation by IFN $\alpha / \beta[31,34]$ and have been previously shown to respond to IFN with a substantial induction of PKR $[2$, 30]. Figure 1a shows that in exponentially growing control cells there is some basal PKR expression before IFN treatment. The pattern of immunofluorescence indicates a marked heterogeneity in expression of the protein within the cell population. In contrast, following exposure to IFN $\alpha$ for 1 day, not only is PKR immunofluorescence strongly enhanced but the cells exhibit a much more homogeneous staining pattern for the protein kinase. There is abundant staining in the rim of cytoplasm surrounding the large nucleus (Fig. 1b). This 

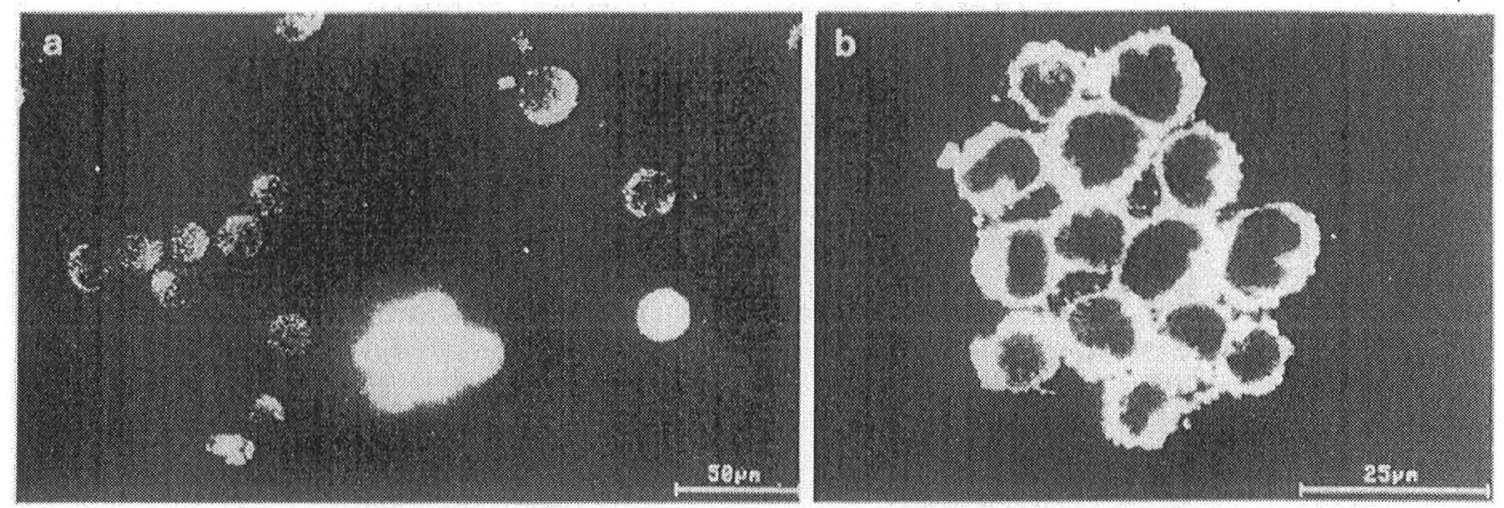

FIG. 1. Analysis of PKR expression in control and interferon-treated Daudi cells by immunofluorescence. Exponentially growing Daudi cells were incubated for $16 \mathrm{~h}$ in the absence (a) or presence (b) of IFN- $\alpha$ (1(10) U/ml). The cells were stained with the monoclonal antibody against human PKR and subjected to analysis by immunofluorescence as described under Materials and Methods.

distribution is similar to that previously reported for another Burkitt's lymphoma cell line, Raji [27]. Close examination of a large number of IFN-treated cells showing strong PKR expression revealed that, in addition to the cytoplasmic staining for PKR, some cells showed staining in their nuclei (Figs. $2 \mathrm{a}$ and $2 \mathrm{c}$ ). In cells in which nucleoli were visible staining was particularly prominent in these regions of the nucleus (Figs. 2c and 2e). Similar results were also seen with Raji cells (data not shown).

The nature and amount of the antibody-reactive material in Daudi cell nuclei were investigated by subcellular fractionation and immunoblotting of the fractions with the anti-PKR monoclonal antibody (Fig. 3). As previously observed [29], the only protein detected on the blots by this antibody was the $68-\mathrm{kDa}$ PKR (a small amount of a PKR breakdown product was detected in the nuclear fraction) (Fig. 3A), Quantitation of the distribution of PKR among nuclei, 12,000g pellet, $100,000 \mathrm{~g}$ pellet (ribosomal), and postribosomal supernatant fractions in both control and IFN-treated cells was performed by a dot-blot procedure using a biotinylated second antibody and $\left[{ }^{125} \mathrm{I}\right]$ streptavidin. Purified recombinant PKR was used as a standard (Figs. $3 \mathrm{~B}$ and $3 \mathrm{C}$ ). Determination of the bound radioactivity in a series of doubling dilutions of the cell fractions, in comparison with the recombinant PKR standard, indicated that in control Daudi cells in exponential growth the minimum level of PKR in the ribosomal and nuclear fractions (not allowing for losses during fractionation) was approximately 560 and $110 \mathrm{ng}$ per $10^{7}$ cells (equivalent to $5.4 \times$ $10^{5}$ and $1.1 \times 10^{5}$ molecules per cell), respectively. Thus the cytoplasmic to nuclear ratio is approximately $5: 1$. Very little PKR was observed in the $12,000 \mathrm{~g}$ pellet or the postribosomal supernatant fractions (not shown). Following IFN treatment of Daudi cells for $16 \mathrm{~h}$ the level of ribosome-associated PKR increased approximately three- to fourfold (to $1880 \mathrm{ng}$ per $10^{7}$ cells), but there was essentially no increase in the amount of PKR associated with the nuclei (Fig. 3C). Thus under these conditions the cytoplasmic to nuclear ratio increased to around 17: 1. Since Daudi cells contain around $100 \mu \mathrm{g}$ rRNA per $10^{7}$ cells, and this value is not changed by short-term treatment with IFN [35], our figures suggest that there is approximately one molecule of PKR for every five ribosomes in these cells prior to IFN treatment. This could rise to approximately one molecule per ribosome after induction of PKR by IFN.

Although the immunoblotting data suggested the absence of cross-reaction with other proteins in the nuclei of Daudi cells, it was possible that there was staining of additional protein(s) that could not be identified on a Western blot. Furthermore, immunological detection of PKR in the nucleus gives no indication of whether the protein kinase activity of PKR is necessary for its localization to this compartment. These questions were approached by using mouse NIH 3T3 cell lines stably expressing either wild-type or catalytically inactive mutant forms of human PKR [19, 32]. The monoclonal anti-human PKR antibody does not recognize mouse PKR [29] and therefore did not stain $3 \mathrm{~T} 3$ cells transfected with a plasmid encoding a neomycin-resistance gene alone (Fig. 4I). In contrast, cells expressing the wild-type human PKR (clone 68.11 [32]) were strongly stained with the antibody. Analysis of single cells by confocal laser scanning microscopy again indicated nuclear as well as cyto. plasmic staining, with strong fluorescence of nucleoli (Fig. 4II). A similar pattern of nuclear and cytoplasmic staining, with strong nucleolar fluorescence, was seen in clone 12.3 cells expressing the mutant form of PKR (Fig. 5). The mutant expressed in these cells contains a single amino acid change (Lys to Arg at position 296) which eliminates all protein kinase ac- 

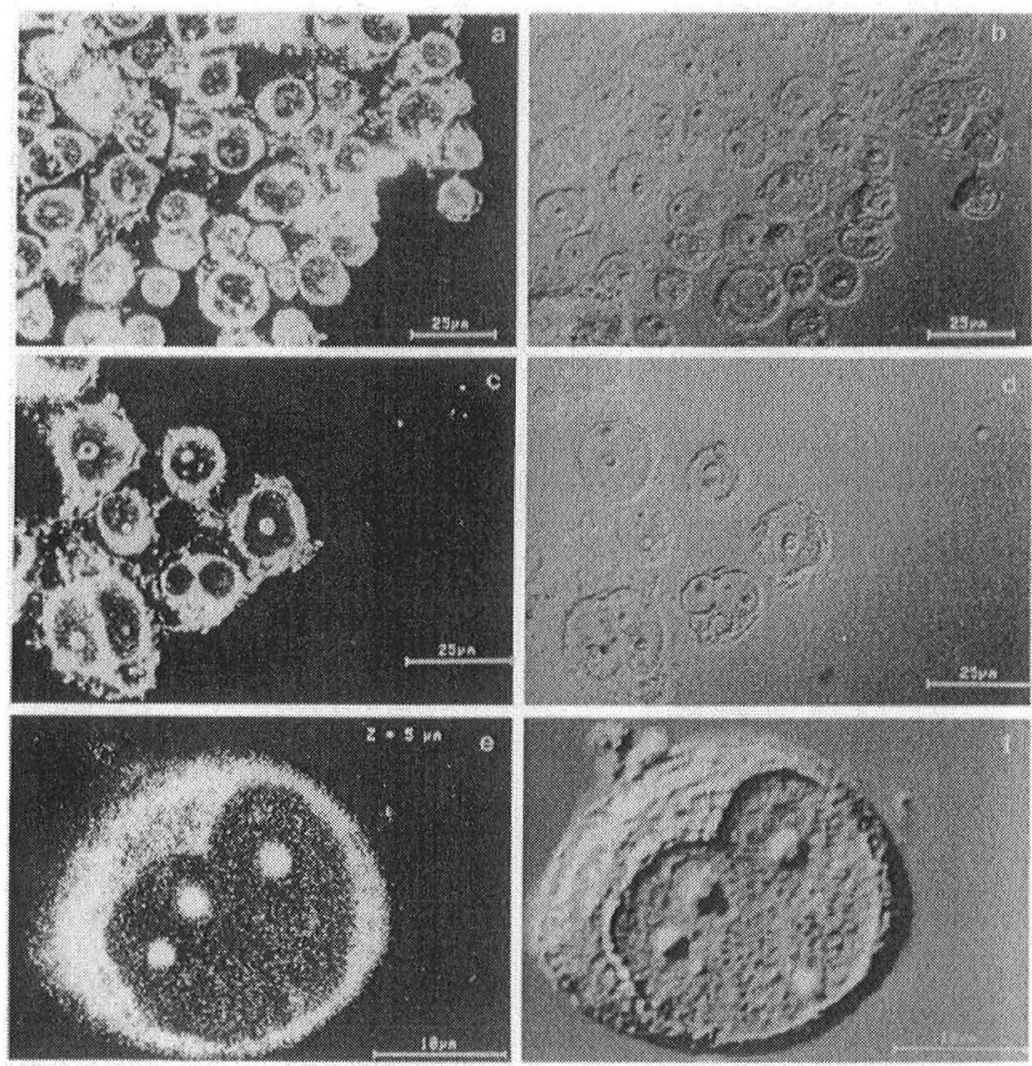

2. Nuclear localization of PKR in interferon-treated Daudi cells. Cells were treated with exogenous IFN as described in the legend to Fig. 1, stained with monoclonal antibody against PKR, and subjected to analysis by immunofluorescence as described under Materials and Methods. (a-d) Large fields of cells shown at low power. (e and f) A single cell shown at high power. (b, $d$, and f) The corresponding phasecontrast images of the cells shown in a, c, and e, respectively.

tivity but does not affect the ability of the protein to bind dsRNA [33]. These results therefore indicate that the nuclear staining observed with the monoclonal anti-human PKR is indeed due to the presence of PKR and suggest that catalytic activity of the protein kinase is not required for the nuclear localization.

Biochemical evidence for the presence of PKR in the nuclei of transfected 3T3 cells was also sought. Using anti-PKR murine polyclonal antibodies, immunoblotting analysis of subcellular fractions of transfected cell clones expressing the wild-type or mutant protein kinase confirmed that a proportion of the PKR was associated with the nucleus in both cases (Fig. 6). Cells transfected with the neo vector alone did not show any immunoreactive band at $68 \mathrm{kDa}$.

We have examined the possibility that, although it has the same apparent molecular weight as cytoplasmic PKR, the nuclear form of PKR may be structurally distinct. For example, specific post-translational modifications may distinguish the forms of the enzyme in these two compartments. It is known that when it is activated by dsRNA PKR undergoes autophosphorylation at multiple sites, a modification which is necessary for its subsequent ability to phosphorylate eIF- $2 \alpha[4,5]$. The presence of covalently modified forms of PKR with different overall charges was investigated by two-dimensional isoelectric focusing analysis of whole cell extracts, followed by Western blotting with the polyclonal antihuman PKR antibodies. In confirmation of previous data [36] the results show that total cell PKR consists of several species with different isoelectric points in the range of $\mathrm{pH} 7$ to 8 (Fig. 7). It has been shown previously [36] that these forms reflect different extents of phos phorylation of the PKR molecule (the amino acid sequence of which predicts a $\mathrm{p} I$ of 8.57 for the unmodified protein). When a nuclear extract was analyzed by the same technique a single predominant species of PKR, with a relatively basic $\mathrm{p} I$ of around 7.9 , was observed (Fig. 7). This suggests that the presence of PKR in the nucleus either results in or is a consequence of underphosphorylation of the protein kinase, compared to the cytoplasmic forms of the enzyme. Note that the poly- 

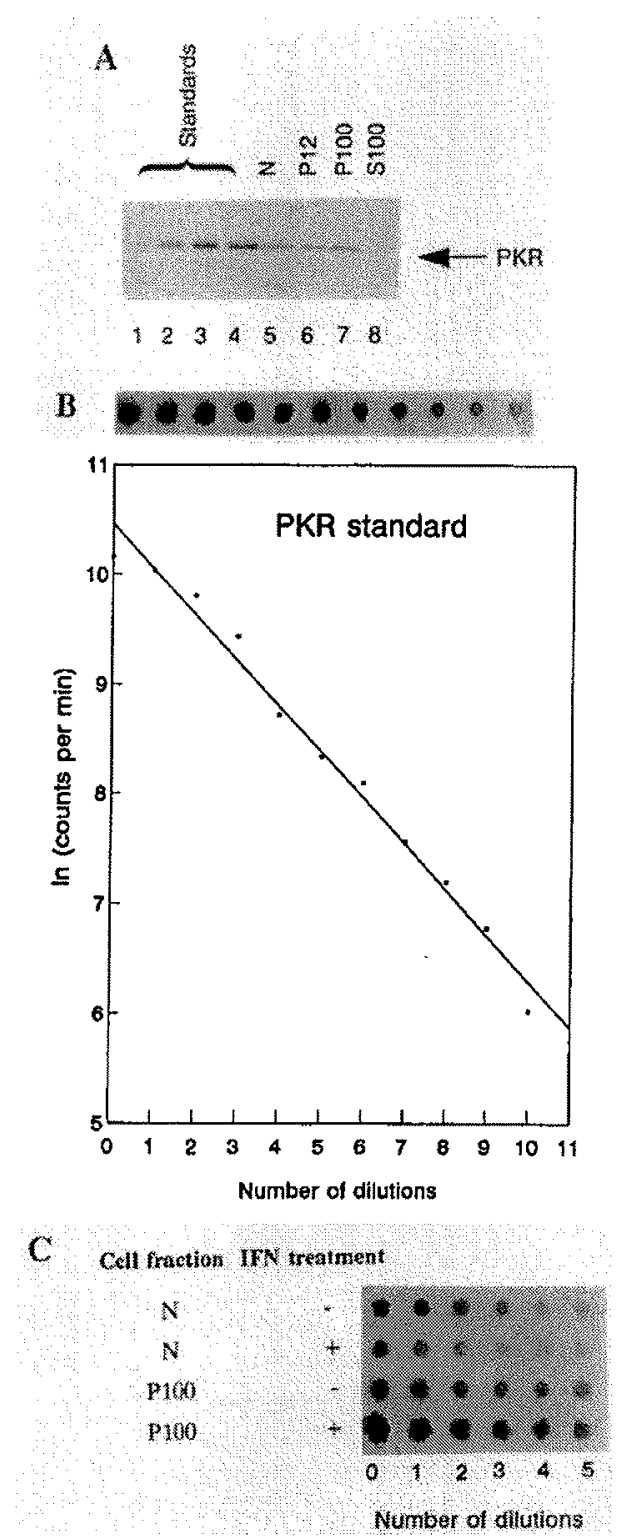

FIG. 3. Immunoblotting analysis and quantitation of PKR in subcellular fractions from control and IFN-treated Daudi cells. (A) Control Daudi cells were grown to a density of $6 \times 10^{5} / \mathrm{ml}$ and cell extracts prepared as described under Materials and Methods. The extracts were fractionated into a nuclear pellet $(\mathrm{N})$, a $12,000 \mathrm{~g}$ pellet (P12), a 100,00)g pellet (P100), and a 100,000g supernatant (S100). These fractions (each equivalent to $10^{7}$ cells) were analyzed by SDSgel electrophoresis and immunoblotting. Different amounts of purified baculovirus-synthesized PKR were run in parallel. The PKR was detected using the monoclonal antibody against human PKR and peroxidase-coupled sheep anti-mouse immunoglobulins. The blot was developed using diaminobenzidine/peroxide reagent. Lanes $1-4,150$, 300,450 , and $600 \mathrm{ng}$ of PKR standard; lanes 5-8, cell fractions as indicated. The position of the $68-\mathrm{kDa}$ PKR band is shown. (B and $\mathrm{C}$ ) Daudi cells at an initial density of $3 \times 10^{5} / \mathrm{ml}$ were incubated in the presence and absence of IFN (100 units $/ \mathrm{ml}$ ) for $16 \mathrm{~h}$ and cell extracts were again prepared and fractionated as above. Doubling dilutions of clonal antibodies used in this experiment, which were raised against urea-denatured purified human PKR, in addition to identifying PKR itself cross-reacted with an IFN-induced protein of $48 \mathrm{kDa}$ and a constitutively expressed protein of $80 \mathrm{kDa}$ (see Refs. [32] and [63] and Fig. 6). These proteins have isoelectric points that are quite distinct from that of PKR. The absence from the nuclear fraction of the $48-\mathrm{kDa}$ protein, which is predominantly a soluble cytoplasmic protein [63], indicates lack of cross-contamination of the nuclei with cytoplasmic proteins in the experiment shown in Fig. 7.

\section{DISCUSSION}

This paper has presented evidence from microscopic analysis and biochemical fractionation studies that the human IFN-inducible dsRNA-dependent protein kinase PKR occurs in both the cytoplasm and nucleus (and specifically the nucleolus) of Daudi Burkitt's lymphoma cells and mouse NIH 3 T3 cells stably transfected with a plasmid encoding human PKR. Our data confirm and extend an earlier report of nuclear and nucleolar PKR in uninfected and adenovirus-infected HeLa cells [37]. Even prior to IFN treatment PKR appears to be a relatively abundant protein (approaching $0.1 \%$ of total cellular protein in Daudi cells). The analysis of PKR levels in nucleus and cytoplasm by immunoblotting, which is consistent with the microscopy data, indicates that approximately $15-20 \%$ of the protein kinase is located in the nuclear compartment. In this analysis the risk of cytoplasmic contamination was minimized by treating the nuclei with $0.5 \%$ Triton $\mathrm{X}-100$, followed by two washes, before the nuclei were lysed. Lack of soluble cytoplasmic contaminants was confirmed by the absence of the crossreactive $48-\mathrm{kDa}$ protein (Fig. 7 ), as well as by assays of lactate dehydrogenase activity (data not shown). Although it is possible that some PKR associated with nuclei isolated in this way is bound to ribosomes on the outer membrane of the nuclear envelope the fact that the

all samples were applied to a nitrocellulose membrane (Amersham Hybond-C) together with a series of PKR standards and the blot was incubated with monoclonal anti-human PKR, biotinylated goat antimouse $\operatorname{IgG}$, and $\left[{ }^{125} \mathrm{I}\right]$ streptavidin. Following autoradiography to locate the dots the amount of bound radioactivity in each sample was measured in a gamma counter. Background radioactivity was subtracted and the data were plotted on a logarithmic scale against the number of dilutions. (B) The autoradiogram and the plot obtained for the PKR standards are shown. The undiluted sample corresponds to $800 \mathrm{ng}$ of PKR protein. (C) The autoradiogram for the nuclear and P100 fractions from control and IFN-treated cells is shown. The undiluted samples correspond to extracts from $1.6 \times 10^{5}$ cells in each case. PKR concentrations in the extracts were calculated from the radioactivity in each series of dilutions, by comparison with the PKR standards, and gave the following values (in nanograms per $10^{7}$ cells): control cell nuclei, 110; IFN-treated cell nuclei, 120; control cell P100, 560; IFN-treated cell P100, 1880. 

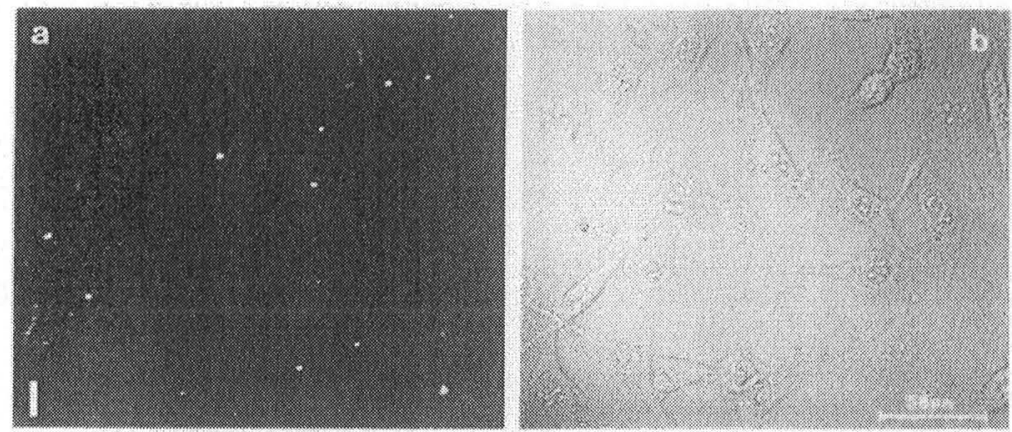

FIG. 4. Staining patterns of human PKR in transfected mouse N1H 3T3 cells. Mouse NIH 3T3 cells that had been stably transfected with the control eukaryotic expression vector pcDNA/neo or with the same vector carrying the wild-type human PKR cDNA sequence (clone 68.11) were stained with monoclonal antibody against human PKR and subjected to analysis by immunofluorescence as described under Materials and Methods. (1) Low-power view of a field of cells transfected with the control vector [immunofluorescence (a) and phase-contrast images (b), respectivelyl. (II) High-magnification analysis by confocal laser scanning microscopy of a cell from clone 68.11 with typical nucleolar staining of PKR. Images a-m represent $1-\mu \mathrm{m}$ sectioning intervals through a single cell. The phase-contrast image of this cell is shown in $n$.

level of nuclear PKR did not increase after IFN treatment of Daudi cells, whereas the ribosome-associated PKR levels are elevated by a factor of three- to fourfold (Fig. 3C), suggests that this pool is not a major source of the PKR identified in the nuclear fraction by immunoblotting. Furthermore, the presence of different isoelectric variants of the protein kinase in the nuclear fraction (Fig. 7) is an indication that these molecules are a discrete subset of the total cell PKR population.

The factors that determine the extent to which PKR localizes to the nucleus and nucleolus remain to be determined. However, the observation of catalytically inactive mutant PKR in the nuclei of transfected cells would suggest that enzymatic activity is not required. It is possible that features in the structure of PKR enable it to enter the nucleus (and more specifically the nucleolus) and there are several potential nuclear (NLS) and nucleolar (NuLS) localization signals $[38,39]$ in the primary sequence of the protein. Examples of possible sequences that may contribute to a NLS are RKAKR at positions 237-241, KRRGEK (380-385), KRTRSK (444-449), and KKEKTLLQKLLSKKPEDR (509$522)$. The latter region, although containing some acidic and hydrophobic residues, conforms to the suggestion [40] that NLS sequences can have a bipartite structure, with clusters of basic residues separated by nonbasic amino acids. Potential NuLS sites (containing critical Q residues) are $R Q K Q$ at positions $18-21, Q K K R$ (110$113)$, and $Q R K \bar{A} K \bar{R}$ (236-241). It will be necessary to transfect into cells forms of the protein in which these various regions have been mutated in order to determine the roles, if any, of these sequences in nuclear and nucleolar localization. It is of interest that two other IFN-inducible proteins which apparently share antigenic epitopes with PKR also contain potential NLS sequences [41]. Another interferon-induced protein, encoded by the Ifi 204 gene in mouse cells, localizes to the nucleolus [42] but the molecular basis for this is not known.

PKR is a protein that binds both to ribosomes $[4,26]$ and to RNA activators and inhibitors [43-49]. The presence of a nuclear form may therefore result from the existence of an appropriate ligand for the protein kinase within the nucleus. PKR-ribosome association may be responsible for the localization of the kinase in nucleoli [50], since this organelle is the site of ribosome assembly and processing, and Jimenez-Garcia et al. [37] have suggested on this basis that PKR may play a role in early ribosome biosynthesis. An alternative, but not mutually exclusive, explanation for the nuclear localization of PKR is that there may be nuclear RNA species (perhaps with a high content of double-stranded structure) that bind the kinase. One possibility is the interaction between PKR and small nuclear or nucleolar RNAs. PKR is known to bind small RNA species such as VA, RNA of adenovirus [10, 51], and EBER-1 and EBER-2 of Epstein-Barr virus [52-54], but its ability to interact with host cell-encoded small nuclear RNAs such as U1, U2, or U4-U6 [55] or small nucleolar RNAs such as U3, U8, or U13 [56] has not been tested. Recently the presence in nucleoli of other transcripts such as c-myc RNA has been reported [57]. Such molecules, which may contain regions with extensive secondary structure, could also constitute potential ligands for PKR. It is of interest in this connection that other RNA-binding proteins such as the viral proteins Rev and Rex have been shown to localize in the nucleolus $[58,59]$.

It is not known whether, in the case of the wild-type enzyme, nuclear PKR is enzymatically active or, conversely, whether its activation is blocked (for example by binding to a small inhibitory RNA). The relatively basic nature of nuclear PKR (Fig. 7) suggests that the enzyme exists in nuclei in an underphosphorylated 

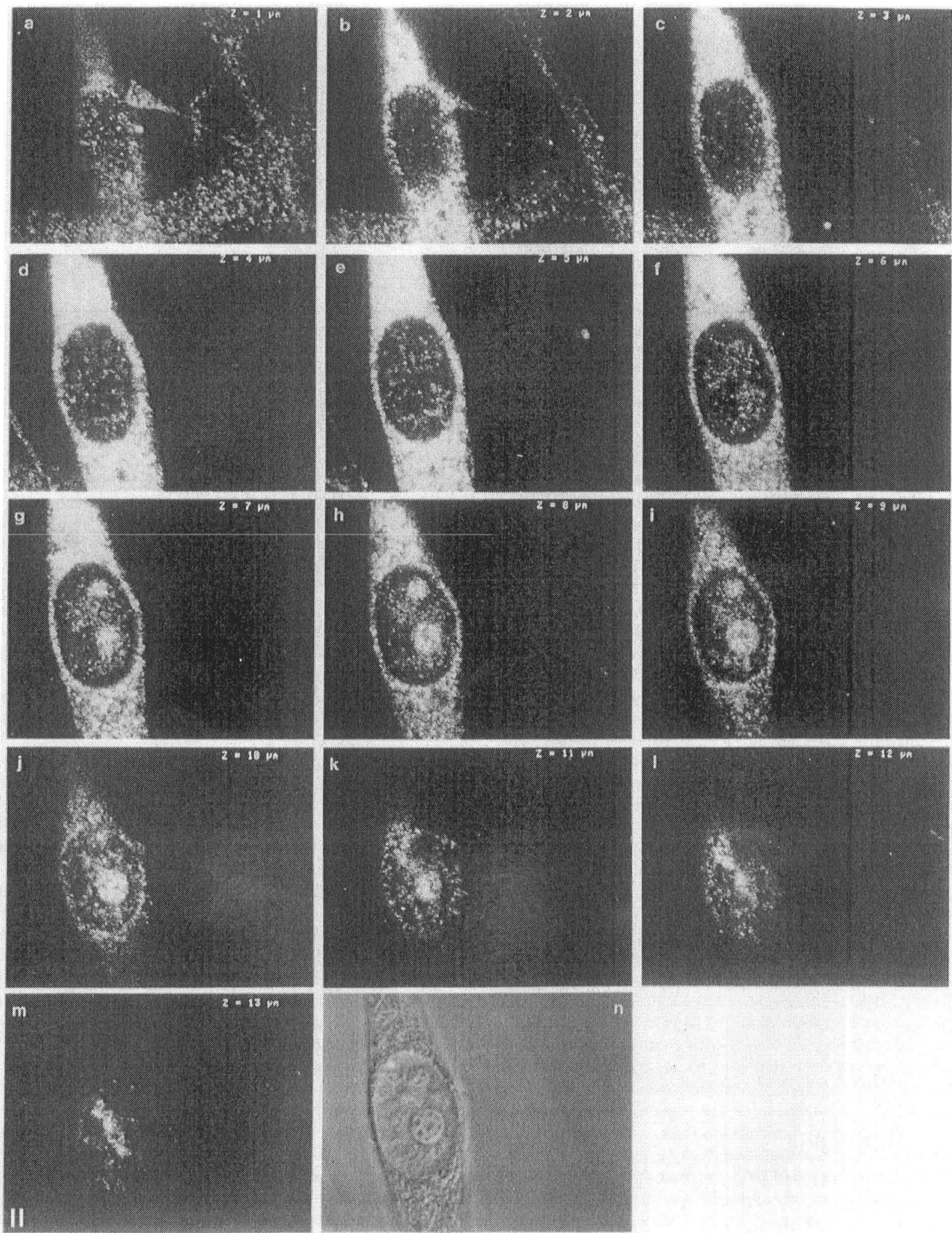

FIG. 4-Continued 

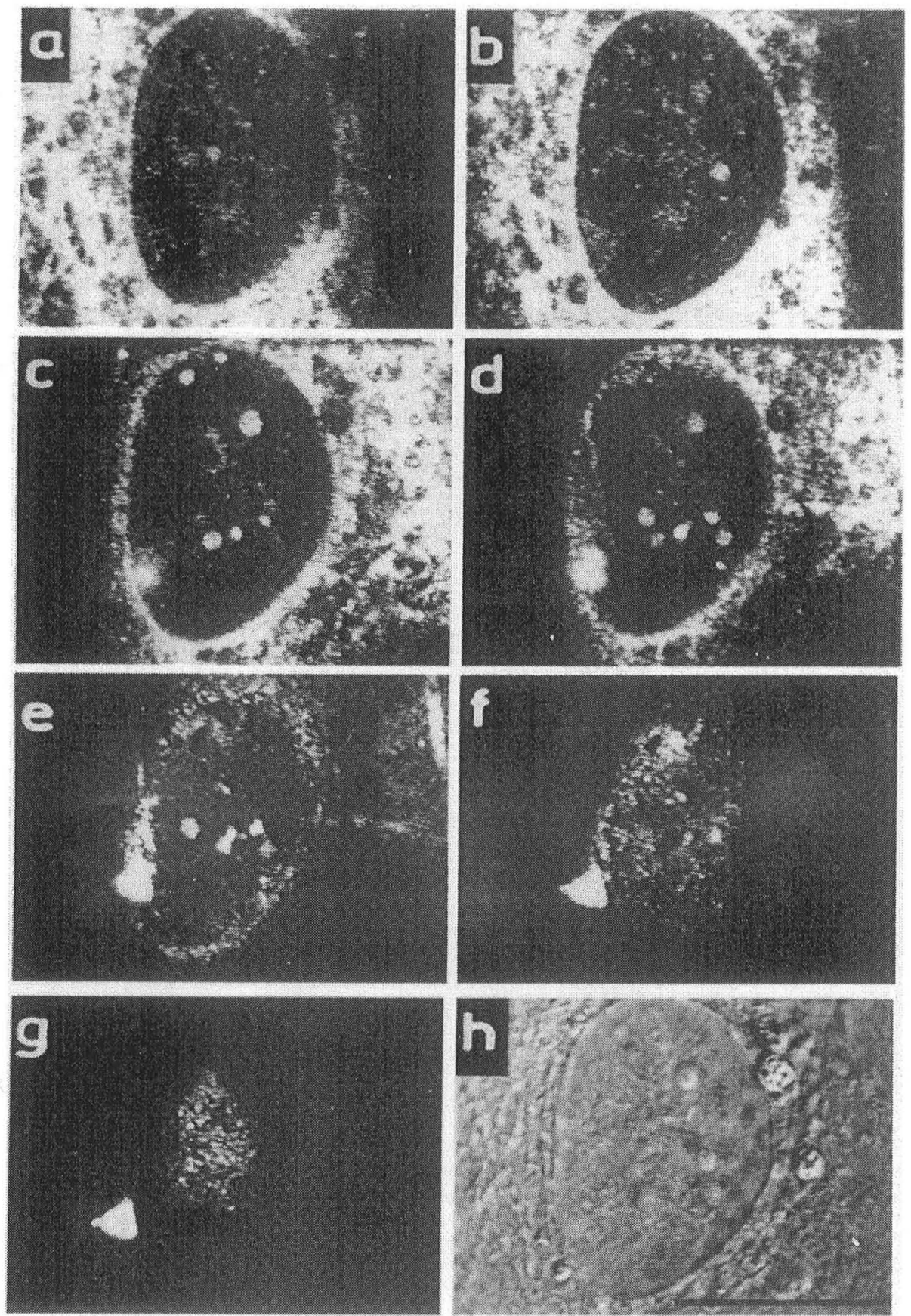

5. Staining pattern of an inactive mutant form of human PKR expressed in transfected mouse NIH 3 T3 cells. Mouse NIH 3 T 3 cells that had been stably transfected with the eukaryotic expression vector pcDNA/neo carrying a cDNA for the K296R mutant form of human PKR (clone 12.3) were stained with monoclonal antibody against human PKR and subjected to analysis by immunofluorescence as described under Materials and Methods. High-magnification analysis by confocal laser scanning microscopy demonstrating nucleolar staining of PKR is shown. a-g represent $0.75-\mu \mathrm{m}$ sectioning intervals through a single cell. The phase-contrast image of this cell is shown in $\mathrm{h}$. Bar, $10 \mu \mathrm{m}$. 
A

\begin{tabular}{|c|c|c|}
\hline Neo & 68,11 & 12.3 \\
\hline & $\mathrm{r} \frac{8}{5} \frac{8}{6}$ & $\mathrm{~T} \approx 8 \%$ \\
\hline
\end{tabular}

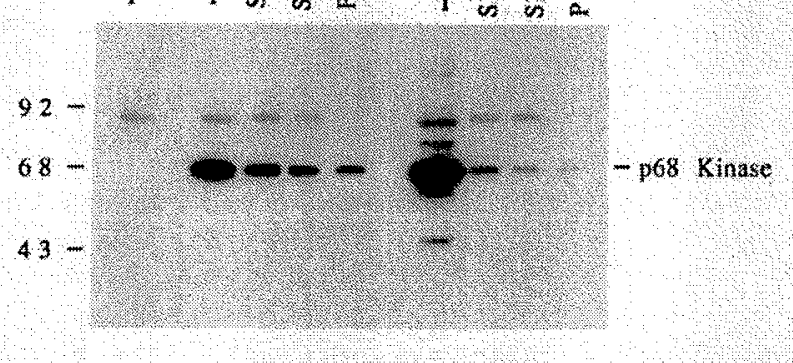

B

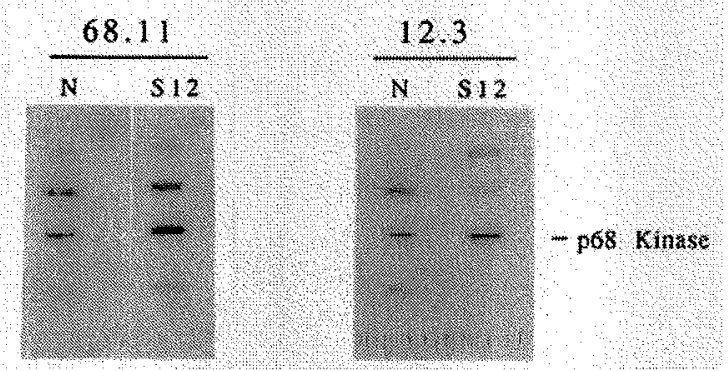

FIG. 6. Levels of human PKR in subcellular fractions of transfected mouse NIH 3T3 cells. NIH 3T3 cell clones that had been stably transfected with vectors expressing wild-type PKR (clone 68.11), the K296R mutant form of PKR (clone 12.3), or a neomycin resistance gene alone (clone neo) were grown as described previously [32]. Confluent cells were scraped and total cell extracts or subcellular fractions prepared as described under Materials and Methods. Each sample (corresponding to material from $2 \times 10^{6}$ cells) was then analyzed for human PKR by SDS-gel electrophoresis and immunoblotting using murine polyclonal antibodies against this protein. (A and B) The results of two different experiments. $T$, total cell extracts; $\$ 12$, $12,000 \mathrm{~g}$ supernatant fraction; S100, $100,000 \mathrm{~g}$ supernatant fraction; P100, 100,000g pellet; $N$, nuclear fraction. (Note that the PKR contents of the total cell extracts cannot be directly compared with those of the subcellular fractions since different buffers were used for sample preparation; extraction of $\mathrm{PKR}$ is more efficient in the case of the total cell extracts.) The positions of molecular mass markers (sizes in kilodaltons) and of the PKR hand (labeled p68 kinase) are indicated.

state, implying that it has not undergone dsRNA-dependent autophosphorylation. This would be consistent with the results with the mutant PKR indicating that protein kinase activity, and thus autophosphorylation, is not a prerequisite for nuclear localization per se. However the $\mathrm{pI}$ of the nuclear form of PKR is lower than the value predicted by the amino acid sequence of the protein, suggesting that even this PKR is not entirely unphosphorylated. It remains to be determined whether autophosphorylation or phosphorylation by other protein kinases of sites close to NLS or NuLS sequences influences the nuclear localization of PKR. The sites in PKR that undergo autophosphorylation have not yet been identified but there is a cdc2 kinase consensus site (KSPEK) near the C-terminus of the protein, close to the putative bipartite NLS; juxtaposition of such sites has been noted previously in nucleoplasmin and other proteins that are targeted to the nucleus [60]. It is also possible that a high level of a PKR phosphatase activity in the cell nucleus might account for the underphosphorylated state of the enzyme, thus maintaining it in an inactive state.

High-level expression of mutant forms of PKR in 3T3 cells results in transformation of the cells to a tumorigenic phenotype [18, 19]. A possible basis for this is that the mutant enzyme exerts a dominant negative effect on a growth inhibitory activity normally mediated by the endogenous wild-type PKR. If such a mechanism is responsible for the tumorigenic effect in vivo the similar subcellular locations of the endogenous and mutant proteins could mean that they compete for specific dsRNA activators or interact with each other in particular critical sites in the cell. Such sites may be nuclear as well as cytoplasmic.

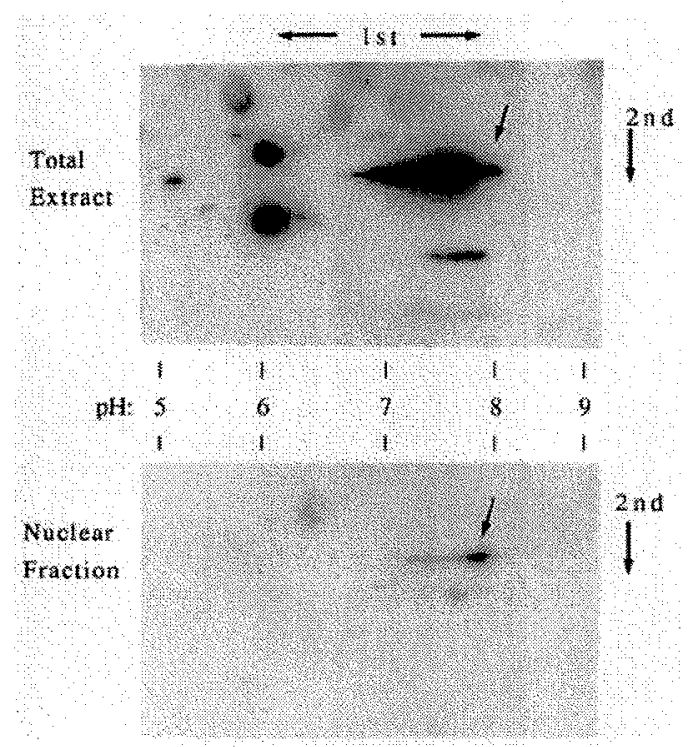

FIG. 7. Isoelectric focusing analysis of total cell and nuclear PKR. Total cell and nuclear extracts were prepared from Daudi cells that had been treated with $500 \mathrm{U} / \mathrm{ml}$ IFN $\alpha$ for $20 \mathrm{~h}$. Samples corresponding to material from $2 \times 10^{6}$ cells were subjected to two-dimensional gel electrophoresis and immunoblotting with murine polyclonal antibodies against PKR as described under Materials and Methods. The directions of the first (isoelectric focusing) and second (SDS) separations are indicated, together with the range of the $\mathrm{pH}$ gradient. The arrows mark the positions of the multiple PKR species with a $I$ range of 7-8 in the total cell extract and of the single PKR species (pI ca. 7.9) that predominates in the nuclear fraction. The spots with a $\mathrm{pl}$ of ca. 6.0 in the upper panel are cross-reacting proteins of 48 and $80 \mathrm{kDa}$ which are recognized by the polyclonal antibodies used in this experiment [see references [32] and (63]). The smal] area of immunoreactive protein below the main PKR region in the upper panel may be a PKR breakdown product $[4,52]$. 
Does the nuclear location of a proportion of cellular PKR mean that there are alternative substrates for this protein kinase? Although elF-2 $\alpha$ is likely to be a major target for the ribosome-associated, cytoplasmic form of PKR it is possible that nuclear proteins may also be phosphorylated if the kinase is capable of activation in the cell nucleus. There is good evidence for direct transcriptional induction of a number of genes (including the IFN genes themselves) by dsRNA [23, 24], and at least some of these effects are blocked by 2-aminopurine, which inhibits PKR activity in vitro [61]. So far there is evidence for the phosphorylation and regulation of only one family of transcription factors by PKR. It has been shown that the $p 50$ form of $N F-k B$ can be activated for DNA binding in vitro by phosphorylation of the regulatory $I_{\kappa} \mathrm{B} \alpha$ protein (MAD-3) [62]. Such a process would be expected to take place in the cytoplasm, where inactive NF- ${ }_{\kappa} B \cdot I_{\kappa} B$ complexes are found, rather than the nucleus. Nevertheless, the possibility of direct PKR-mediated nuclear regulation of other transcription factors remains. If the genes that are transcribed under the control of such factors themselves encode critical cell cycle regulatory proteins this may provide a mechanism for the modulation of cell proliferation by PKR and for the disruption of normal growth control in the presence of mutant forms of this protein kinase.

We are very grateful to Drs. G. Barber and M. Katze (University of Washington, Seattle) and Dr. D. Gewert (Wellcome Foundation, Beckenham) for provision of the recombinant baculovirus expressing mutant PKR and for help in the preparation of the protein. This research was supported by grants from the Cancer Research Campaign (Grants SP 1951/0501 and SP 1951/0601), the Wellcome Trust (Grant 031488) and the Sylvia Reed Cancer Fund (to M. Clemens) the Deutsche Forschungsgemeinschaft (Grant Ba 1145/1-2) (to $M$ Bachmann), and the Association de la Recherche sur le Cancer (to A. Hovanessian). M. Schwemmle is a recipient of an Isaac Lindenmann Scholarship and M. Bachmann is a recipient of a professorship granted by the "Hermann-and-Lilly-Schilling Stiftung" in the "Stifterverband für die Deutsche Wissenschaft."

\section{REFERENCES}

1. Pestka, S., Langer, J. A., Zoon, K. C., and Samuel, C. E. (1987) Annu. Rev. Biochem. 56, 727-777.

2. Hovanessian, A. G. (1989) d. Interferon Res. 9, 641-647.

3. Samuel, C. E. (1991) Virology 183,1-11.

4. Galahru, J., and Hovanessian, A. G. (1987) J. Biol. Chem. 262, 15538-15544.

5. Kostura, M., and Mathews, M. B. (1989) Mol. Cell. Biol. 9, 15761586.

6. Farrell, P. J., Balkow, K., Hunt, T., Jackson, R. J., and Trachsel, H. (1977) Cell 11, 187-200.

7. Proud, C. G., Colthurst, D. R., Ferrari, S., and Pinna, L. A. (1991) Eur. J. Biochem. 195, 771-779.

8. Pain, V. M. (1986) Biochem. J. 235, 625 637.

9. Hershey, J. W. B. (1991) Annu. Rev. Biochem. 60, 717-755.

10. Mathews, M. B., and Shenk, T. (1991) J. Virol. 65, 5657-5662.

11. Katze, M. G. (1992) J. Interferon Res. 12, 241-248.
12. Clemens, M. J., Laing, K. G., Jeffrey, I. W., Schofield, A., Sharp, T. V., Elia, A., Matys, V., James, M. C., and Tilleray, V. J. (1994) Biochimie 76, 770-778.

13. Watson, J. C., Chang, H.-W., and Jacobs, B. L. (1991) Virology 185, 206-216.

14. Chang, H.-W., Watson, J. C, and Jacobs, B. L. (1992) Proc. Natl. Acad. Sci. USA 89, 4825-4829.

15. Lloyd, R. M., and Shatkin, A. J. (1992) J. Virol. 66, 6878-6884.

16. Roy, R., Katze, M. G., Parkin, N. T., Edery, I., Hovanessian, A. G., and Sonenberg, N. (1990) Science 247, 1216-12L.

17. Chong, K. L., Feng, L., Schappert, K., Meurs, E., Donahue, T. F., Friesen, J. D., Hovanessian, A. G., and Williams, B. R. G. (1992) EMBO J. 11, 1553-1562.

18. Koromilas, A. E., Roy, S., Barber, G. N., Katze, M. G., and Sonenberg, N. (1992) Science 257, 1685-1689.

19. Meurs, E. F., Galabru, J., Barber, G. N., Katze, M. G., and Hovanessian, A. G. (1993) Proc. Natl. Acad. Sci. USA 90, 232236.

20. Clemens, M. (1992) Nature 360, 210-211.

21. Sharp, T. V., Xiao, Q., Jeffirey, I, Gewert, D. R., and Clemens, M. J. (1993) Eur. J. Biochem. 214, 945-948.

22. Hovanessian, A. G., Laurent, A. G., Chebath, J., Galabru, I., Robert, N., and Svab, J. (1987) EMBO J. 6, 1273-1280.

23. Visvanathan, K. V., and Goodbourn, S. (1989) EMBO J. 8, 11291138.

24. Wathelet, M. G., Berr, P. M., and Huez, G. A. (1992) Eur. J. Biochem. 206, 901-910.

25. Maran, A., Maitra, R. K., Kumar, A., Dong, B., Xiao, W., Li, G., Williams, B. R. G., Torrence, P. F., and Silverman, R. H. (1994) Science 265, 789-792.

26. Dubois, M. F., and Hovanessian, A. G. (1990) Virology 179, 591 598.

27. Schwemmle, M., Clemens, M. J., Hilse, K,, Pfeifer, K., Tröster, H., Müller, W. E. G, and Bachmann, M. (1992) Proc. Natl. Acad. Sci. USA 89, 10292-10296.

28. Levin, D., and London, 1. M. (1978) Proc. Natl. Acad. Sci. USA $75,1121-1125$.

29. Laurent, A. G., Krust, B., Galabru, J., Svab, J., and Hovanessian, A. G. (1985) Proc. Natl. Acad. Sci. USA 82, $4341-4345$.

30. Meurs, E., Chong, K., Galabru, J., Thomas, N. S. B., Kerr, 1. M. Williams, B. R. G., and Hovanessian, A. G. (1990) Cell 62, 379390.

31. Clemens, M. J., and Tilleray, V. J. (1986) Biochem. J. 237, 877884.

32. Meurs, E. F., Watanabe, Y., Kadereit, S., Barber, G. N., Katze, M. G., Chong, K., Williams, B. R. G., and Hovanessian, A. G. (1992) J. Virol. 66, 5805-5814.

33. Barber, G. N., Tomita, J., Garfinkel, M. S., Meurs, E., Hovanes. sian, A., and Katze, M. G. (1992) Virology 191,670-679.

34. Gewert, D. R., Shah, S., and Clemens, M. J. (1981) Eur. J. Bio. chem. 116, 487-492.

35. Clemens, M.J., McNurlan, M. A., Moore, G., and Tilleray, V. J. (1984) FEBS Lett. 171,111-116.

36. Krust, B., Galabru, J., $_{\text {, }}$ and Hovanessian, A. G. (1984) J. Biol. Chem. 259, 8494-8496.

37. Jimenez-Garcia, L. F., Green, S. R., Mathews, M. B., and Spector, D. L. (1993) J. Cell Sci. 106, 11-22.

38. Chelsky, D., Ralph, R., and Jonak, G. (1989) Mol. Cell. Biol. 9, 2487-2492.

39. Garcia-Bustos, $d$, Heitman, J., and Hall, M. N. (1991) Biochim. Biophys. Acto 1071, 83-101. 
40. Dingwall, C., and Laskey, R. A. (1991) Trends Biochem. Sci. 16, $478-481$.

41. Kadereit, S., Gewert, D. R., Galabru, J., Hovanessian, A. G., and Meurs, E. F. (1993) J. Biol. Chem. 268, 24432-24441.

42. Choubey, D., and Lengyel, P. (1992) J. Cell Biol. 116, 1333-1341.

43. Galabru, J., Katze, M. G., Robert, N., and Hovanessian, A. G. (1989) Eur. J. Biochem. 178, 581-589.

44. Katze, M. G., Wambach, M., Wong, M-L., Garfinkel, M., Meurs, E., Chong, K., Williams, B. R. G., Hovanessian, A. G., and Barber, G. N. (1991) Mol. Cell. Biol. 1 1, 5497-5505.

45. Feng, G., Chong, K., Kumar, A, and Williams, B. R. G. (1992) Proc. Natl. Acad. Sci. USA 89,5447-5451.

46. Patel, R. C., and Sen, G. C. (1992) J. Biol. Chem. 267, 76717676.

47. McCormack, S. J., Thomis, D. C., and Samuel, C. E. (1992) Virology $188,47-56$

48. Green, S. R., and Mathews, M. B. (1992) Genes Dev. 6, 24782490.

49. Manche, I.., Green, S. R., Schmedt, C., and Mathews, M. B. (1992) Mol. Cell. Biol. 12, 5238-5248.

50. Meier, U. T., and Blobel, G. (1992) Cell 70, 127-138.

51. Katze, M. G., DeCorato, D., Safer, B., Galabru, J., and Hovanessian A G (1987) EMBO J 6, 689-697.
52. Clarke, P. A., Schwemmle, M., Schickinger, J., Hilse, K., and Clemens, M. J. (1991) Nucleic Acids Res. 19, 243-248.

53. Clemens, M. J. (1993) Mol. Biol. Rep. 17, 81-92.

54. Sharp, T. V., Schwemmle, M., Jeffrey, I., Laing, K. G., Mellor, H., Proud, C. G., Hilse, K., and Clemens, M. J. (1993) Nucleic Acids Res. 19, 4483-4490.

55. Mattaj, 1. W. Tollervey, D., and Séraphin, B. (1993) FASEB J. 7, 47-53.

56. Tyc, K., and Steitz, J. A. (1989) EMBO J. 8, 3113-3119.

57. Bond, V. C., and Wold, B. (1993) Mol. Cell. Biol. 13, 3221-3230.

58. Cullen, B. R., Hauber, J., Campbell, K., Sodroski, J. G., Hasel tine, W. A., and Rosen, C. A. (1988) J. Virol. 62, 2498-2501.

59. Siomi, H., Shida, H., Nam, S. H., Nosaka, T., Maki, M., and Hatanaka, M. (1988) Cell 55, 197-209.

60. Robbins, J., Dilworth, S. M., Laskey, R. A., and Dingwall, C. (1991) Cell 64, 615-623.

61. Zinn, K., Keller, A., Whittemore, L-A., and Maniatis, T. (1988) Science 240, 210-213.

62. Kumar, A., Haque, J., Lacoste, J., Hiscott, J., and Williams, B. R. G. (1994) Proc. Natl. Acad. Sci. USA 91, 6288-6292.

63. Kadereit, S., Galabru, J., Robert, N., Meurs, E. F., and Hovanessian, A. G. (1994) J. Interferon Res. 14, 251-257. 